Article

\title{
Entrapment within Inner Space: The Development and Review of Other Materials as Intentional Inclusions within Glass as a Creative Artistic Practice
}

\author{
Jessamy Kelly ${ }^{1, *(D)}$ and Goshka Bialek ${ }^{2}$ \\ 1 School of Design, Edinburgh College of Art, The University of Edinburgh, Edinburgh EH3 9DF, UK \\ 2 Independent Artist, Durham DH1 4ED, UK; goshkab@gmail.com \\ * Correspondence: jessamy.kelly@ed.ac.uk
}

Citation: Kelly, Jessamy, and Goshka Bialek. 2021. Entrapment within Inner Space: The Development and Review of Other Materials as Intentional Inclusions within Glass as a Creative Artistic Practice. Arts 10: 5. https://doi.org/10.3390/arts10010005

Received: 1 October 2020 Accepted: 5 January 2021 Published: 15 January 2021

Publisher's Note: MDPI stays neutral with regard to jurisdictional clai$\mathrm{ms}$ in published maps and institutional affiliations.

Copyright: () 2021 by the authors. Licensee MDPI, Basel, Switzerland. This article is an open access article distributed under the terms and conditions of the Creative Commons Attribution (CC BY) license (https:// creativecommons.org/licenses/by/ $4.0 /)$.

\begin{abstract}
This paper will introduce the use of intentional inclusions and inner space within glass as a means of creative expression, as an emerging area of practice-based research within the field of art glass. This includes the definition of key concepts, a short history of inclusions in glass, the development of technologies used by material scientists working with inclusions and the industrial applications of inclusions in glass will be discussed. This paper will discuss the completed doctoral research of Jessamy Kelly who explored ceramic inclusions within glass and Goshka Bialek who explored metal inclusions within glass. Both glass artists explored the use of foreign, intentional inclusions which have been entrapped within glass within their doctoral research. Glass artists that use a variety of metal, ceramic and other inclusions to penetrate the internal space of their objects will also be introduced. This paper will set the parameters of the field providing an in-depth study into the concept and use of inclusions which plays an important part in understanding why some glass artists use inclusions within their glass. It is significant to recognise a collective response, from many artists detailed in this paper and their exploration of the internal space within art glass objects, to create an inner space or world within their artworks. This paper will define and explore the variety of ways, both from a historical and contemporary perspective, that inclusions in glass, have been combined together over many years.
\end{abstract}

Keywords: inner space; inclusions; glass; ceramic; metal; ariel; inlaid colour; glass; hot state; art glass

\section{Introduction}

This paper will discuss the completed doctoral research of Jessamy Kelly (2009) and Goshka Bialek (2017) and will draw on the common research theme of "inclusions in glass". An inclusion within glassmaking can be defined as any foreign material that is intentionally or unintentionally trapped in a hot state inside glass during its formation. The inclusions to be discussed within glass are ceramics (Kelly 2009) and metal (Bialek 2017) both researchers have used inclusions which have been entrapped within kiln cast and blown glass artefacts. Both of these practice-based research projects were carried out in the United Kingdom at the University of Sunderland between 2004 and 2017. The researchers overlapped with one another during their studies, connecting with one another over time.

The further research that has stemmed from these doctoral projects will be introduced and a discussion about the combined impact that these projects have had on the field of contemporary art glass. This paper will propose a new joined up discourse on the use of inclusions (foreign materials) in glass, which can be viewed as a contextualised study that Kelly and Bialek have collectively extended and challenged the boundaries of material research around the development and application of inclusions within glass. This is the first time this research has been viewed in parallel and discussed as an inter-related and connected disciplinary approach. This paper will discuss an emerging studio movement that is driven by the study of inclusions and inner space in glass. 
This paper hopes to provide a new perspective and context to the doctoral research projects and the subsequent post-doctoral work. Viewed not in isolation (as previously published) but viewed alongside each other as inter-connected projects developed iteratively over the doctoral study time frame (2009-2017). Each project has had impact on the subsequent work and has contributed to the extended field of doctoral study within the field of art glass. Each researcher has developed their own highly specialised creative art glass practice as a result, with innovative outputs and future findings for the field. This paper will also explore the continued impact that each of these research projects have had on the field of art glass, by presenting a range of case studies that introduce a diverse selection of practitioners that have gone on to apply and, in some cases, extend the "inclusion" techniques developed by these projects. This paper draws primarily on the $\mathrm{PhD}$ theses of the two named authors Kelly and Bialek, and is brought up to date with a range of extensive interviews undertaken by the authors with artists and material scientists in the field of glass, who work with inclusions and inner space within creative practice.

The focus of Kelly's (2009) research was to investigate the combination of glass and ceramics in studio practice, focused specifically on the hot state inclusion of ceramic elements within kiln cast and blown glass. The research concentrated on the use of pre-fired ceramic (bone china) inclusions in cast and blown glass. The focus of Bialek's (2017) research was to investigate methods of combining metal and glass, specifically concentrating on the application of a variety of metals within glass, including composites of metals, pure metals, alloys and metal oxides combined with different glass techniques, for creative studio practice. The research was concentrated on the use of inner space in sculpture and the use of metal inclusions within glass.

Within their doctoral research, both researchers found that formal research and publications in this field were disparate and limited; and that obtaining information from practitioners about their application methods for the use of other material inclusions in glass was difficult, with many not wishing to share their techniques. A high degree of uncertainty was surrounded around the subject of inclusions and the related results. Many glass students are told to avoid adding inclusions to their glass, as they can be very difficult to understand and control and can lead to cracks and stresses within the glass. Both researchers were told during their earlier, undergraduate education that foreign material inclusions were a problem that required extended, postgraduate study. This paper will explore solutions to combining other material inclusions within glass that the authors have discovered within their own artistic practice as well as the investigations of other glass practitioners in the field who combine other material inclusions in their glass work. This approach is premised on the view that all inclusions in glass require knowledge and practice in their application, as well as an in-depth understanding of the material and processing technologies of glass.

\subsection{Jessamy Kelly}

In 2009, Jessamy Kelly completed her practice-based PhD at the University of Sunderland which investigated the use of ceramic inclusions within glass. The research created a range of artworks that combined glass and ceramics in a hot state within blown and kiln cast glass (Figures 1 and 2). The research project developed a new recipe of ceramic material that was compatible with glass, that has been shared and used as a model for other practitioners in the field, examples of which will be discussed in Section 6. 


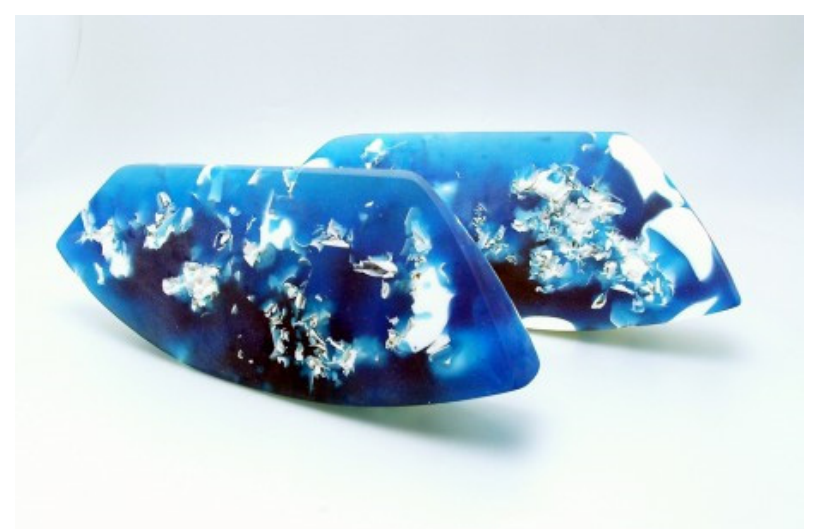

Figure 1. Jessamy Kelly; Wedge; 2009; turquoise and clear, kiln cast glass sculpture with compatible pre-fired bone china aggregate inclusions; photo credit: the artist, used with permission.
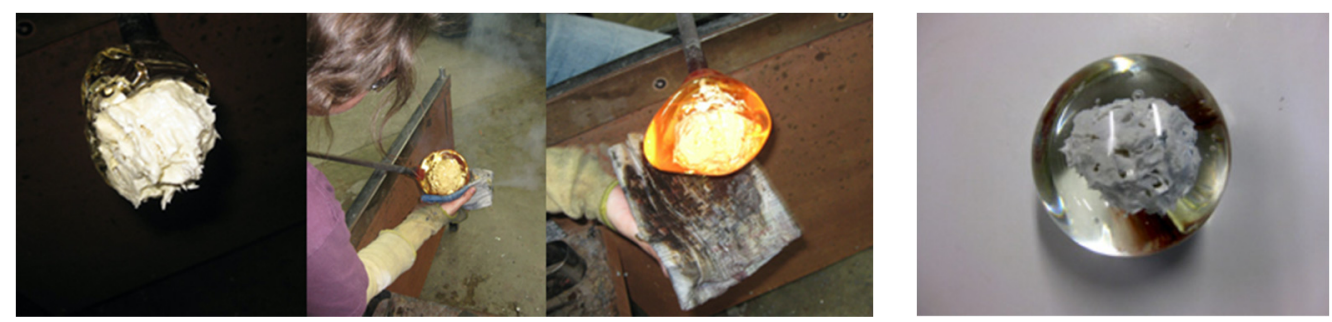

Figure 2. Jessamy Kelly and Criss Chaney; 2009; blown glass paperweight with compatible pre-fired bone china core inclusion; photo credit: the artist, used with permission.

\subsection{Goshka Bialek}

In 2017, Goshka Bialek completed her practice-based PhD at the University of Sunderland which investigated the use of metal inclusions in kiln cast glass. Her thesis was an exploration of the Inner space in sculpture through the application of inclusions, particularly metal inclusions within glass (Figure 3). Her doctoral research was a continuation of her master's research (2003) which developed innovative methods of applications of other media, including print, holograms and 3D collages, as inclusions within cast glass. She went on to develop an extended palette of metals that can be used within glass and a range of methods for applying the metal inclusions.

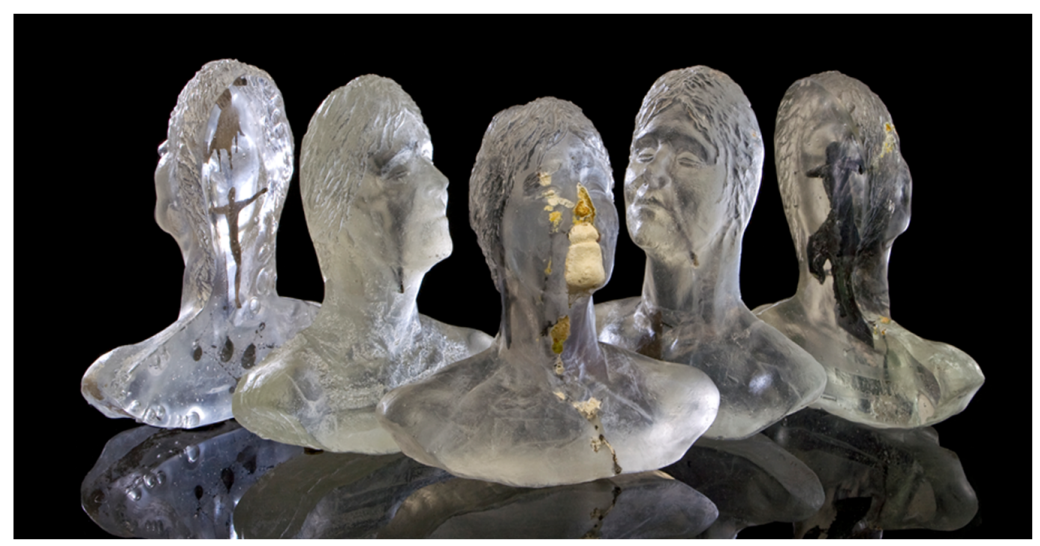

Figure 3. Goshka Bialek; self-psychoanalysis V; 2017; variety of inclusions in glass: using water jet cut nickel, tin and lead alloy sheets, gallium and silkscreen printings, cast hot glass into moulds; photographed by David Williams. Used with permission. 
Inclusions are the most basic and well-known tool used by glass artists to work with the internal space of glass objects, adding contrast through colour, texture and form. However, the application of inclusions creates many technological problems within artistic practice. This paper will concentrate on the methods used to combine glass with other materials and will consider the subject from both historical and contemporary perspectives. Firstly, Section 2 will define inclusions in glass and give a brief history with historical to present day examples, including the limitations of using inclusions. Section 3 will discuss the industrial applications for glass, metal and ceramic inclusions. Section 4 will discuss how artists and technologists learn from serendipitous happy accidents and "failure" within their work to advance the field. Sections 5-7 will discuss a range of artistic work that combines inclusions, categorizing how each discussed "inclusion" type is determined and used within the field. The work of these artists will be defined as an emerging body of practice-based research in which artists are collectively exploring the internal space of glass for creative expression through the use of intentional inclusions. Finally, Section 8 will summarise and conclude the article.

\section{The Definition of Inclusions in Glass}

According to the Oxford Advanced Learner's Dictionary "inclusion" is defined as "the action or state of including or of being included within a group or structure" (Oxford Advanced Learner's Dictionary 2014). The Corning Glass Dictionary (2002) defines inclusions within glass as "a collective term for bubbles, metal and glass particles, and other foreign materials that have been added to the glass for decorative effects". Regularly in material science, inclusions are defined as "strange particles" contained in the main body. During the creation of glass these imperfections, known as inclusions, are accidentally caught within the structure of the glass in the initial heating process. However, inclusions are defined most aptly by Clark-Monk and Parker: "Inclusions in glass have been both a scourge and a fascination to the glass maker for centuries" (Clark-Monks and Parker 1980, p. 2). In summary, inclusions are anything that can be fused between layers of the main body of an object and these foreign particles and materials add colour, depth or texture to the object. Bray defined inclusions as "a general term for materials or bubbles incorporated into glass objects as decoration. Industrially, this also refers to faults in the glass" (Bray 2001, p. 141). The Retro Art Glass (2014) states that "inclusions can be classified as unintentional or intentional". An unintentional inclusion is usually the outcome of an accidental contamination during the creative process. Unintentional contamination can be a trapped air bubble, dust from a mould or kiln, a refractory stone in the furnace glass, raw material, or a gas bubble on the surface. Alternatively, artists can deliberately add foreign objects to the glass and intentionally control the whole process, which we will define as an intentional inclusion. In general, both kinds of inclusions are detrimental to the mechanical properties of glass but much depends on their number, size, shape and distribution. Throughout history, glass artists have experimented with inclusions that have unidentified co-efficients of expansion and have different qualities from that of glass; which in turn can cause defects such as stresses and cracks to appear within the glass, either immediately or slowly over time.

\subsection{The History of Inclusions in Glass}

To understand how inclusions were applied and why, we need to know the history of the application of glass with other materials and the use of inclusions by man from the beginning, approximately four thousand years ago (Matsuo 1998, p. 18). Glass and unintentional inclusions have been known to humans since the Stone Age (from 3.4 million years BCE to 8000-2000 BCE), cave people made tools and weapons from natural volcanic obsidian glass which contained (unintentional) metal inclusions. Most glass historians are agreed that techniques for making glass were first discovered in the Bronze Age around the end of the third millennium BC. The process of melting and casting metal would already be known and this knowledge would have been useful in the production of glass. 
Humans have been producing glass by melting raw materials for thousands of years. First beads, which were supposed to be substitutes for semi-precious and precious stones, were the most common glass products, but glass rods, inlays and other richly coloured items were also produced (Grose 1989, p. 8). Researchers from the Corning Museum of Glass noticed that it was at the very beginning of the emergence of glass that inclusions were introduced (Brill and Moll 1963, p. 294). This does not mean that these inclusions were always added intentionally. The first inclusions probably occurred accidentally in the glass, because they were in the sand or other components used in the process. Today, it is possible to investigate ancient glass objects with modern scientific instruments. For example, an electron beam probe can perform microanalyses of glass, including its inclusions, this technological advancement makes it possible to identify the substance and properties of ancient glasses.

Researchers from the Advance Metals Research Corporation, USA (Brill and Moll 1963, p. 296) analysed different kinds of coloured glass in several objects and mosaic plaques of the Roman period. During this investigation inclusions of microscopic dimensions were found in Roman ancient glass. Several stones, opacifying agents, metallic inclusions, and weathering crusts were further studied in this research. Analysis of ancient Roman glass demonstrates that opacifying agents were intentional inclusions containing iron oxide, cuprous oxide, potassium, magnesium, aluminium and lead oxides. Analysis of glass from later periods between the 5th and 12th centuries has shown the presence of tin and lead (Brill and Moll 1963, p. 297). Commonly, the inclusions in ancient glass were applied predominantly as colorants and opacifiers. It has been observed that at that time only a few metals were used intentionally as inclusions. Grose (1989, p. 25) mentions two examples of inclusions: slabs of glass with the inclusion of gold leaf and the inclusion of gold used in the Mesopotamian star-a disc pendant from the 15th century BC. These kinds of products were more frequently used by Romans for vessel manufacture or wall mosaics (Grose 1989, p. 34). Gold and gold foil were the first metal inclusions used in glass. A most notable example of this being the Lycurgus cup, a Late Roman drinking-cup from the 4th Century, made from dichroic glass. The cup looks green when light shines on it but red when light shines inside it, as it contains tiny nanoparticles of gold and silver. Other inclusions of precious metals like silver or platinum and less precious metals like copper and copper alloys have also been found. The first glass item inlaid with an inclusion is dated from the 16th century, made in Bohemia, it was a glass goblet with ivory inclusions. At the same time more craft glass products with the inclusions of medals, metal coins and other objects emerged. However, this type of object was made by employing a cold glass manufacturing process (Hartwig 2014). This means that a foreign object was enclosed in the hollow in an earlier shaped piece of glass then covered with a second piece of flat glass. In discussion with Bayley (2014) it was noted that demand for creating inclusions with imitation antiquarian objects originally began after the excavations of the sites of Pompeii and Herculaneum in the 18th century, which elevated curiosity about classical art. The increasing demand for neo-classical objects was the main reason for the development of these techniques. For this purpose, Bohemian craftsmen conceived the innovative concept of the encasement of porcelain in hot glass. This technique was perfected and patented by Apsley Pellatt in 1819 (Jokelson 1968, p. 7). These porcelain Cameo inclusions in hot glass were called sulphides because they had the same appearance as silver sulphide.

The history of glass and ceramics is closely interwoven, for thousands of years, glass and ceramics have been closely linked through the process of glazing on ceramics. Egyptian paste dates from the end of the fifth millennium B.C. it is a non-clay ceramic made mainly of quartz or sand which was made into beads that looked like semi-precious stones and is one of the earliest forms of glaze found on ancient ceramic objects, such as beads, amulets and scarabs. Egyptian perfume bottles and vases are among the first examples of core formed objects where glass objects are formed around a soft core containing ceramic and other materials such as dung; the core is then removed leaving a hollow glass form. These techniques indicate that the origins of glass making developed directly from ceramic 
processes and would likely have had unintentional ceramic particles trapped within the glass as small material inclusions.

Most notably, in 1740, Rene Réaumur carried out extensive research on the chemical composition of Chinese porcelain; motivated by the famous letters of D'Entrocelles (17121722) relating to the composition of Chinese hard paste porcelain. He developed an opaque glass known as Réaumur porcelain a type of crystalline ceramic which today would be classified as a "glass-ceramic". Réaumur proposed rather to take ordinary window glass and pack it densely in a powder of calcined gypsum and quartz, a mixture which maintained the shape when it softened and also nucleated crystal growth from the surface. Sealed in a fired ceramic container and fired in an ordinary terracotta kiln, the glass crystallized to form what has been referred to as Réaumur's porcelain, and described as a "fibrous" glass (Kingery 1986, p. 171). Glass-ceramics were not formally identified until 1952, when material scientist Stanley Stookey accidentally discovered glass ceramics at the Corning Glass works when a furnace containing glass accidentally overheated and a glass-ceramic was formed.

Until the work of Kelly (2009) and Bialek (2017), there was very limited formally published literature on the combination of glass with other material inclusion such as a metal or ceramics in studio practice. Bray (2001) is a practical resource aimed at studio practitioners. However, it does not show examples or practical methods of how to combine glass with metals or ceramics. Within the literature, it is very difficult to find information about the applications of inclusions in glass; it is hoped that this combined paper will rectify this gap.

As part of the PhD of Bialek (2017), interviews with glass specialists from different organizations such as the Corning Museum of Glass, the Rakow Library, the Society of Glass Technology, the British Glass Society and Krakow Academy of Technology, were carried out. An interesting historical example of metal inclusions in hot glass was discussed by art historian Justine Bayley, who specialises in glass and metal. The inclusion of valuable coins in a few antique Roman glass pieces was discussed. The main known examples of enclosed Romans coins are only ceramic replicas of coins in glass mostly from the 18th or 19th century. Another example of experimental production of coin replicas was introduced during World War II when copper was needed for ammunition in America (as the original coins were made from copper). The Blue Ridge Glass Company in Tennessee made experimental pennies using tempered glass with coin impressions and metallic colour inclusion.

\subsection{The Studio Glass Movement and Inclusions}

The 1960s brought about a dramatic transformation of glass, with the advent of the studio glass movement and the development of glass studios set up and run by independent artists. This movement became the driving force in the development of new techniques in the production of glass, including experiments with inclusions. In 1962, the US ceramicist Harvey K. Littleton led workshops and seminars on hot studio glass. Littleton in collaboration with Dominick Labino, a research chemist, developed a formula for glass that could be melted at a low enough temperature in a single-pot furnace (Layton 1996, pp. 26-30). This innovation set the scene for the international studio glass movement which led glass making away from the factory, creating a new generation of independent studio glass artists. This movement towards an independent route of artistic expression started to blur the boundaries between craft, design and fine art. It is important to experiment and push boundaries so that glass art does not become stale or predictable. In the last two decades, glass artists have dramatically changed the nature of what had been considered as glass art. As these boundaries merged so did the boundaries between studio glass and the use of other material inclusions in the work such as ceramics and metals, opening up new creative possibilities in the medium. During this period of open experimentation, it became natural for artists to combine glass with metal, clay, bronze, 
wood or other foreign materials. The use of intentional inclusions within artistic practice can be traced to this period and extends to the present day, as discussed in this paper.

In 1979, the Corning Museum of Glass organized the first major international New Glass exhibition, within the catalogue introduction Thomas Buechner, states that a dramatic change was taking place in the history of glass, after thirty-five centuries of utilitarian use of this medium. The Studio Glass movement has been characterised by the exchange of ideas between artists and provides artists with possibilities to explore applications of new materials as inclusions in glass. Thanks to the radical development of studio glass technology, artists could advance using inclusions in their artistic practice and publications on the subject became available to a wider audience. However, only metals which had been used as metal inclusions by artisans in the past (such as copper, gold, silver), were exploited by the artists in their artistic practice, probably owing to the unsatisfactory results obtained from experiments with other metals, as discussed by Bialek (2017). From the very beginning, the Studio Glass movement was international, and many conferences and workshops were organised by and for glassmakers to have an opportunity to exchange ideas. Some of these events addressed the different applications of glass, as well as the combination of glass with other materials. Many new aspects have come to enrich artists' way of viewing glass as an art medium and by experimenting with and using mixed media, other materials can be used as intentional inclusions within glass.

\subsection{Limitations in Using Inclusions}

Most studio glass artists have limited knowledge about chemistry, physics and material engineering, which can be a barrier when artists wish to incorporate new materials and technology successfully into their work. Many artists will be faced with cracks and stresses in their work due to material incompatibility. A lack of technical knowledge can also hinder their communication with industry experts. A range of questionnaires and interviews with glass artists and educators were carried out. Analysis of the questionnaires (produced by Kelly (2009) and Bialek (2017)) confirmed this view, providing key insights into the types of inclusions artists were using in glass. A range of discussions were carried out to expand a discourse into the use of inclusions in glass with groups of artists through online forums and networks. From this substantial review of the field, it is known that the list of known inclusions is quite extensive and artists are working with a range of mixed media and glass. However, knowledge about some of the media, is still limited and a distinct lack of formalized research was identified in the field by both Kelly (2009) and Bialek (2017).

Prior to the publications of Kelly (2009) and Bialek (2017), many higher educational institutions would not have advised students to mix their glass with foreign material inclusions. Departments that specialise in glass and ceramics did not encourage the mixing of the two materials as they create incompatibilities, stresses and cracks in the materials. Experiments relating to these issues are described in detail by the PhD thesis of Kelly (2009). Likewise, departments that specialise in glass and metals, stipulate the use only of "metals that are compatible with glass-these being copper, aluminium in varying forms: sheet, wire, mesh, etc., or nicrothal wire" (Chrysopoulo 2014). Handbooks and publications for glass artists emphasize that for the best results, they should use an object that is thin and light. This will allow the fusing glass to expand and contract around the piece. Assuming that this is true, the thickness and weight of the object suitable for immersion in the glass needed to be determined. Experiments relating to these issues are described in detail by the PhD thesis of Bialek (2017).

The most common metal inclusion in glass used by artists around the world is copper, due to the changeable and aesthetically pleasing results it creates in terms of colour, texture and pattern. Precious metals such as gold, silver, platinum and palladium are familiar metal inclusions in glass and most textbooks for glass students include information about them, although they are obviously expensive to use. Studio glass artists often incorporate thin copper, metal leaf, aluminium, brass, nickel metal oxides, chrome and nichrome as 
inclusions inside their glass. Fused glass artists such as Ruth Lyne and Jo Downs work in this way. Lundstrom (2011) introduces fusing methods in his book "Kiln Fired GlassCopper \& Metal Inclusions" which gives an excellent introduction to fusing techniques. Extensive practice-based research into the use of metal oxides within glass casting should also be noted, the research of Vandenhoucke (2003), Stewart (2010) and Brachlow (2012) are significant doctoral contributions to the field. Metal is an incredibly versatile material: from high-tech lightweight aluminium to air-purifying titanium dioxide, and from crude and raw Corten steel used in marine transportation through to gold leaf. Applications of metal inclusions into hot glass involve techniques with the most unpredictable results. To control these processes requires material experience, knowledge and ability, and even more knowledge to experiment and push boundaries. A table has been created below that classifies the types of inclusions used in glass; this can be seen as a concise overview of the field (see Table 1).

Table 1. Classification of inclusions in glass.

\begin{tabular}{|c|c|}
\hline \multicolumn{2}{|r|}{ List of Materials Used for Inclusions in Glass by Glass Artists } \\
\hline Glass & $\begin{array}{l}\text { Coloured glass, beads, threads, glass powders, bearing glasses, "glow-in-the-dark" } \\
\text { powder, sand, beach glass, etc. Glass frit, glass inlay (Keeryong 2016), } \\
\text { flameworked glass inclusions. }\end{array}$ \\
\hline Organic & $\begin{array}{l}\text { Dried plant materials, leaves recycled plants, reactive earth, brown-green earth, } \\
\text { plant materials, sea shells, human and animal remains (bone). }\end{array}$ \\
\hline Ceramic & $\begin{array}{l}\text { China clay, vintage plates, some pottery "washes", Egyptian Paste, stoneware, } \\
\text { terracotta, porcelain, bone china (Kelly 2009). }\end{array}$ \\
\hline Images & $\begin{array}{l}\text { Integrated glass printings, printed transfers, direct screen-printing onto the glass, } \\
\text { hand paint images, holograms, 3D printed collages, sandblasting, etching, } \\
\text { photographs, digital and laser prints (Bialek 2000, 2003). }\end{array}$ \\
\hline $\begin{array}{l}\text { Metals and metallic } \\
\text { materials }\end{array}$ & $\begin{array}{l}\text { Mixed glass containing reactive metals, such as copper, lead, sulphur, selenium, to } \\
\text { produce reactions; copper dust, copper thread and wire, copper leaf and sheet, } \\
\text { silver leaf, gold leaf, brass silver foil, gold foil, palladium, brass, copper wire } \\
\text { reclaimed from old electrical items, thread, wire, shavings and sheet, aluminium } \\
\text { foil and sheet, palladium, rusty metal found on the beach, dichroic extracts } \\
\text { (metals: lead, sulphur, copper, and selenium), oxides (chrome green, cobalt blue, } \\
\text { vanadium yellow), nichrome, iron mesh, zinc, steel and related alloys, metal coins } \\
\text { with a fairly low melting point (Walker 2010). } \\
\text { Gallium, Lead and Tin alloys, Iron, Nickel-Silver, Aluminium, galvanized Iron, } \\
\text { Chromium and its alloys, stainless steel, Cobalt, Invar, Kovar, pure Nickel and its } \\
\text { alloys: Nickel with } 19 \% \text { Cobalt, Nickel with dominance of Cobalt, Nickel with } \\
\text { Chromium, Nickel Alloy 825, Cronifer } 1925 \text { hMo-Nickel Alloy } \\
\text { 926-superaustenitic stainless steel with the molybdenum and nitrogen contents } \\
\text { (Bialek 2017). }\end{array}$ \\
\hline Other & $\begin{array}{l}\text { Kaiser enamels, Glassline, Bullseye thinfire paper, fibre paper, mica, bubble agents, } \\
\text { air bubbles (Flavell 2001) and (Mitchell 2015) flexible glass, concrete, } \\
\text { semi-transparent concrete, lights. }\end{array}$ \\
\hline
\end{tabular}

\section{Industrial Applications for Glass, Metal or Ceramic Inclusions}

Industrial applications for glass and metal combinations range from domestic products such as the light bulb to aerospace industry components. Glass was recognised as an excellent medium to bond or seal with many metals and their alloys, initially copper, silver, gold, and later iron, nickel, chromium and cobalt alloys. The inclusion of gold foil in glass has been employed for many centuries, and the sealing of platinum through glass has long been practiced by craftsman and technologists. However, the vitreous enamelling of iron or inclusions of metals in glass are a comparatively recent development, powdered glass is fused to a substrate to create a durable vitreous enamelled surface that is protected from damage. This was first utilised on a commercial scale in the electric-lamp industry, which still employs this technology (Donald 2009, p. 14). The use of glass to metal seals in industry has focused attention on the need for studies of the many problems involved. As a result, substantial progress has been made in the techniques of joining glass to metal, so that today there is a wider choice of suitable glasses and metals; however, some of them 
are only available at the industrial level. Some of these techniques and materials are too expensive and too difficult to employ by artists within studio practice.

Stones (from batch) and cords (from melting) are often viewed as unwanted inclusions in hot glass. Decades of research and centuries of glass making brought practice to a point where glass today is of very high quality and usually free of stones, with techniques for identifying and rapidly isolating most unwanted inclusions which occur in glass. For artists, this experience could turn into a happy accident and become a new technique in their artistic practice. Bang Espersen intentionally added stones, brick and window glass to her blown glass series "Things change" (2015), placing the object in a state of constant tension, which eventually creates stresses and cracks within her work over-time as the glass reacts to the incompatible materials (see Figure 4).
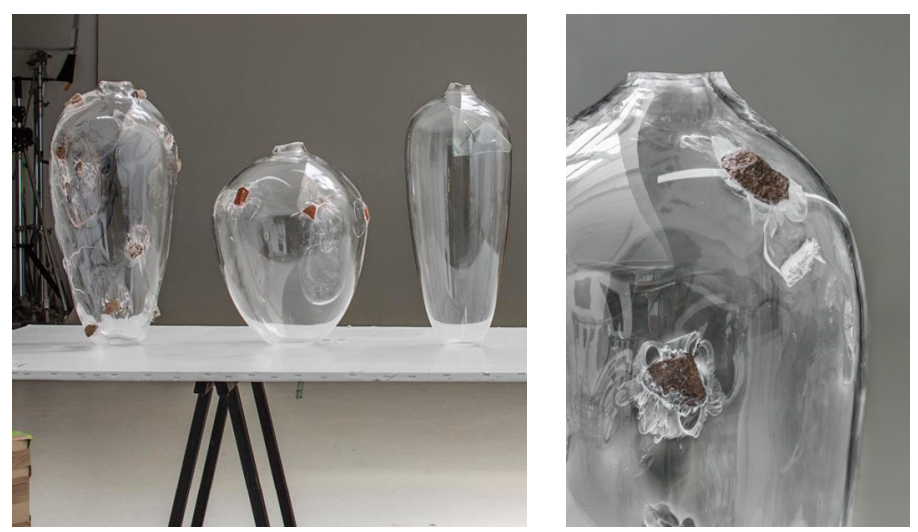

Figure 4. Maria Bang Espersen, "Things Change", glass, brick, window glass and rock, 2015 approximately $53 \mathrm{~cm} \times 30 \mathrm{~cm} \times 25 \mathrm{~cm}$ each, photo credit: courtesy of the artist, used with permission.

The research of industrial glass technologists into unwanted inclusions is described by Clark-Monks and Parker in their book Stones and Cord in Glass (Clark-Monks and Parker 1980), metal stones, such as lead, iron or various metal alloys which contain chromium, cobalt or nickel, affect glass and how they can be recognised. The doctoral research of Bialek (2017) improves our understanding of the reaction of metal inclusions with glass and enables us to choose suitable techniques for managing them.

Industrial applications for glass and ceramic combinations also range from domestic products such as the glass-ceramics used in cookware, to highly scientific objects made out of glass-ceramics such as radomes, telescope mirrors and insulators. Glass can partially convert into a ceramic form when processed in a controlled way to create a glass-ceramic material (Strnad 1986, p. 9). This is a controlled process of crystallisation and creates materials which have low or negative coefficient of expansion making them shock resistant. If not prepared with a controlled temperature schedule, this process is known as devitrification, when small unintentional particles of dust or dirt are left on the surface of the glass and nucleate to create an unstable form of glass-ceramics, with visible cracks and stresses. There appears to be no evidence of this process being used by studio practitioners. A great deal of research is being carried out into the considerable possibilities and potential of glass ceramics but as yet there is little sign of them being exploited in a studio. Many glass ceramics also require rather high melting conditions and more accurate controls than are likely to be found in the small studio or workshop (Bray 2001). It was clear that glass-ceramics were beyond the parameters of the research project. This was due to the specialist equipment needed to facilitate such an enquiry; the high temperatures and controls required to create glass-ceramics are beyond the provision of a studio environment. It was agreed that the research project should be approached using viable studio materials and processing techniques only. 


\section{Learning from Serendipitous Happy Accidents and "Failure"}

This section will deal with artists' who have unsolved problems with the foreign materials used as inclusions within their glass practice. A series of artist interviews revealed that technological limitations are, in some cases, the reason why some of their preliminary ideas were not developed further. Artists do not necessarily discuss their "failures" openly because they do not see them as failures, only as a challenge to their practice. Although there is a desire among both artists and industry to develop the technology for including foreign materials such as metal or ceramics within glass, the road to perfection is viewed by them very differently. Yet, for both industry and artists, "failure" through trial and error can be a key developmental step forward. In industry, there have been notable examples of "failure" which have moved forward the application of joining metal (aluminium) with glass. Some aluminium alloys react with glass and at high temperature they form substances with a structure like volcanic rocks. The experimentation of Bernadeta Procyk at the Technology Academy in Krakow is of specific note; she carried out extensive testing with aluminium and glass casting; from these experiments she developed an insulating material.

In the 19th century artists used porcelain objects, some of which were replicas of ancient metal coins or medals. This visual effect is created by a residual micro air layer between the ceramic cameo and the lead glass. It is caused by the incorrect inlay of the cameo porcelain within the glass. In this situation, again the imperfection turned into a very unusual artistic design. However, it was noticed that this interesting phenomenon also appears on the surfaces of some metals which are employed in other research. This phenomenon helps to reduce stress between the glass and the inclusion of the applied medium during the cooling process. Glass and metal have often been employed by artists, even though this combination is unpredictable, difficult to control and can lead to failures in compatibility. It was also common for small stones to be accidentally incorporated into glass; in the production of architectural glass, these nickel sulphide impurities often led to damage. Today, nickel sulphide is treated during the cooling process so that it is less likely to crack under the pressure of a large surface area. In addition, thermally toughened glass has replaced heat strengthened glass to eliminate this problem and controlled insertions are now intentionally added to glass for decoration. Indeed, it is believed that glass itself was discovered by accident. Throughout the studio glass movement, the early development of glass art was based upon serendipitous, happy accidents and failures. The history of both artistic studio glass work and industrial glass are full of creative challenges to overcome and trials that have led to other opportunities and new creative innovations.

In the next section, a range of artistic work that will be discussed that can be viewed as an emergent studio movement driven by studying inclusions within glass. The following examples can be defined as an emerging body of practice-based research in which artists are seen to be exploring the internal inner space of glass for creative expression through the use of intentional inclusions.

\section{Artists Combining Glass with Metal Inclusions in a Hot State, within Their Artistic Practice}

This section is a review of selected glass artists that combine glass with metal inclusions in a hot state within their artistic practice. The following glass artists will be discussed: Keith Cummings, Uta Majmudar, Paul Stankard, Bertil Vallien and Markku Salo.

\subsection{Keith Cummings}

Cummings is an internationally renowned glass artist, educator and writer on the subject of kiln-formed glass. He studied Fine Art at the University of Durham (1958-1962), where he started to first explore glass (see Figures 5 and 6). He has been working with glass and metal for almost fifty years, but he is conscious that both he and the materials have changed during this time. He plays a central role in the history of glass artists' education in the UK. His first publication "The Technique of Glass Forming" (1997) is 
still the most important publication for students, as are his many preceding publications. He advocated the use of glass-forming methods which looked back to Mesopotamian, Egyptian and Roman techniques, but he also presents new glass-making techniques in his publications (Cummings 2002, Cummings [1997] 2007, 2009a, 2009b). He also writes about inclusions (Cummings [1997] 2007, pp. 67-71) and conventional decorative materials for lamination, particularly enamels and glass powders, fibre glass, ceramic glaze oxides, air, some metals and organic materials. In his books, he encourages readers to experiment with other materials in order to get unexpected results (Cummings [1997] 2007, p. 71). The metals which Cummings mentions in his publications are mostly used as a decorative function of coloured glass. He also briefly mentions the applications of metals in the form of powder, foil or wire. Mostly he describes how to work with copper, because, in his opinion, this metal is the easiest and most predictable. He mentions that other metal foils can be used providing they are thin, and therefore weak enough to allow the glass to expand. Cummings indicates the problem of glass fused "to the surface of the metal due to the wetting action of the glass during fusion" and the problem of oxidation of metals during the heating process (Cummings [1997] 2007, p. 69). However, he does not explain further these significant problems, nor does he give any solutions.

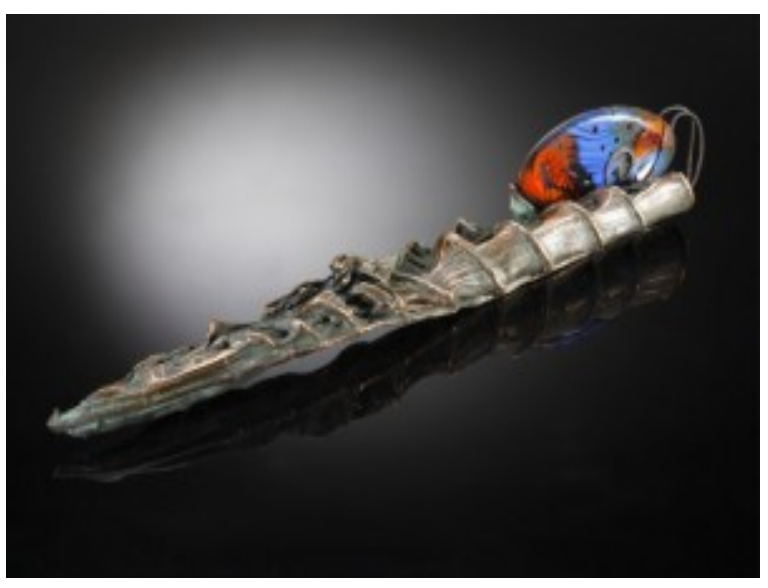

Figure 5. Keith Cummings; Pennant, 1998; glass and bronze, bronze applied to wax model, wax steamed out and glass cast into mould; photo credit: Simon Bruntnell, used with permission.

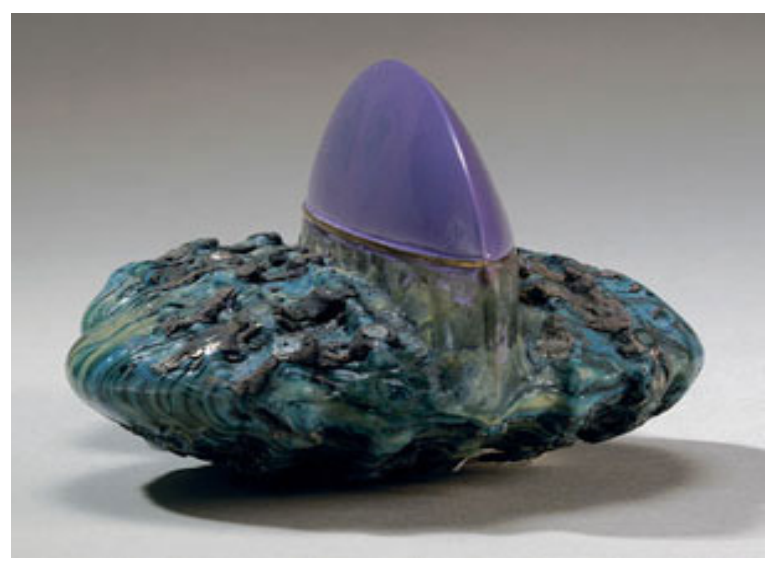

Figure 6. Keith Cummings; Crest, 2002; cast bronze applied to wax model, wax steamed out and glass cast into mould with pre-cast and polished kiln-formed glass element; courtesy of the artist, used with permission.

\subsection{Uta Majmudar}

Majmudar specialises in flameworking, when blowing borosilicate tubes with a lamp, she makes colours with metal oxides, instead of the usual colourless glass. Between two 
tubes she uses silver nitrate for a yellow colour, cobalt oxide for blue, chromium for green and copper which makes either red (with lots of air) or brown. She also uses silver foil, cut into figures between tubes and uses copper, silver, gold and stainless-steel wire within her work (see Figure 7). Her difficulty has been to keep glass pieces together in certain forms, so, she has used metals not only to give colour, but also to give strength to certain forms.

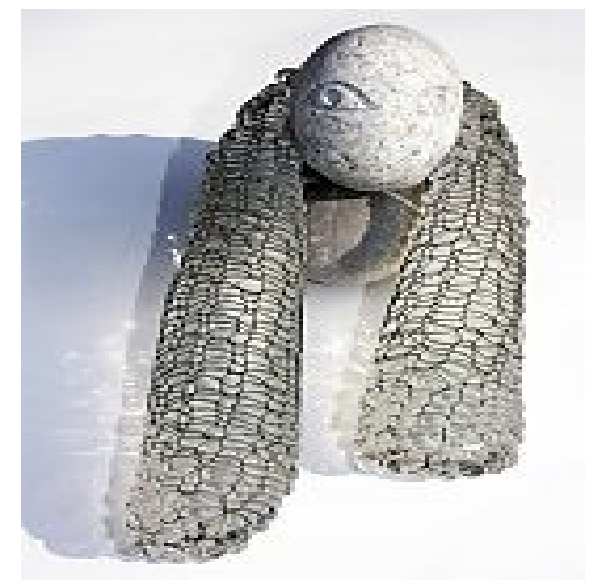

Figure 7. Uta Majmudar; Streckt die Arme, 2007, glass and metal wire, hot fused. Courtesy of the artist, used with permission.

\subsection{Paul Stankard}

Stankard works with metal oxides to add colour to his objects and is renowned for his flame-worked floral motifs expressed in crystal paperweights, rectangular columns and orbs. He was trained in scientific glassblowing and worked in industrial scientific glass during the 1960s. Challenged by an inner sense of creativity and the need to establish his creative independence, he started making paperweights in the early 1970s. He uses flameworked coloured glasses to make his botanical components as inclusions, to encapsulate the designs into clear glass; he also uses metal inclusions (Figure 8). Fine gold leaf is used to suggest the ethereal or spiritual relationship to the natural world. His inclusions are quite large, up to two inches in diameter before encapsulation in clear glass. Paul Stankard discusses his problems with the application of larger metallic inclusions in the glass and describes how he solved his problems by using thin wire or gold leaf. As can be seen, even artists with technical education solve their problems by reducing the size of their inclusions.

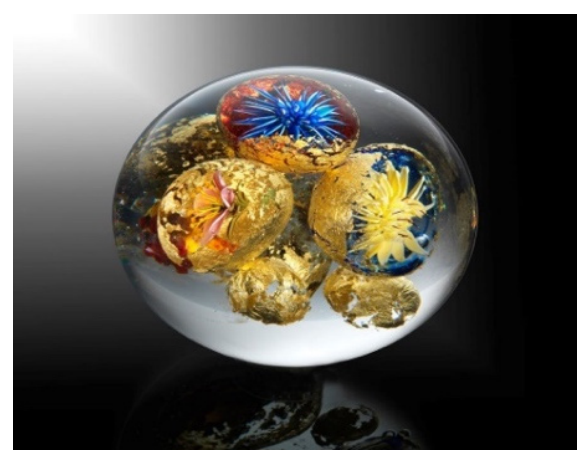

Figure 8. Paul Stankard; Golden Orbs Floating in a Sphere, 2008; gold inclusion within hot flameworked glass; photo credit: Ron Farina, used with permission.

\subsection{Bertil Vallien}

Vallien first worked with glass when he began to work as a glass designer for Afors in 1963 and went on to work with Kosta Boda; "He is a man who understands a factory" 
(McGregor 1997, p. 8). The sand-casting process gives him the opportunity to use glass in a more personal way without size restrictions (see Figure 9). Vallien is conscious that over-exploitation of decorative inclusions (he calls them "cheap effects") can be a reason for losing real meaning. For him the quality of the glass is not important, he uses lead crystal glass as it is easy to anneal and soft enough for cold working. He uses coloured glass powders, enamels, found objects, little sculptures pre-cast in glass, and metals. $\mathrm{He}$ has experimented with silver, iron and other metals but chose copper because it seemed to work the best. He is aware of copper's different rate of expansion from glass, but it is accepted by glass as an implant. Sometimes, he uses quite thick rods and bits of copper but mostly inclusions in the shape of small figures are made from $0.15 \mathrm{~mm}$ copper sheet.

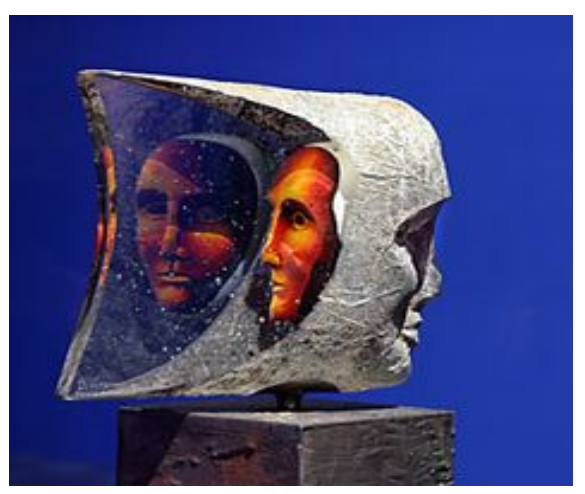

Figure 9. Bertil Vallien; Janus, 2011; sand cast glass sculpture with copper and colour oxides inclusions; courtesy of the artist, used with permission.

\subsection{Markku Salo}

Salo works with the Nuutajärvi glassworks in Finland and is renowned for his large glass sculptures employing steel structures and intended for public spaces, and his amusing bottles blown into steel netting. Salo uses metal net in order to give an additional outer surface to the glass object in contrast to the inner (see Figure 10). In his opinion, one way to find a new perspective is to combine glass with other materials. In addition to the metal nets, he has combined glass with wood, rock and "technics" (industrial robots). He also uses metal in his larger works as a structural material. In this situation, the metal is not usually on the surface; its main duty is to support the other parts of the artwork. He uses black metal and ordinary steel.

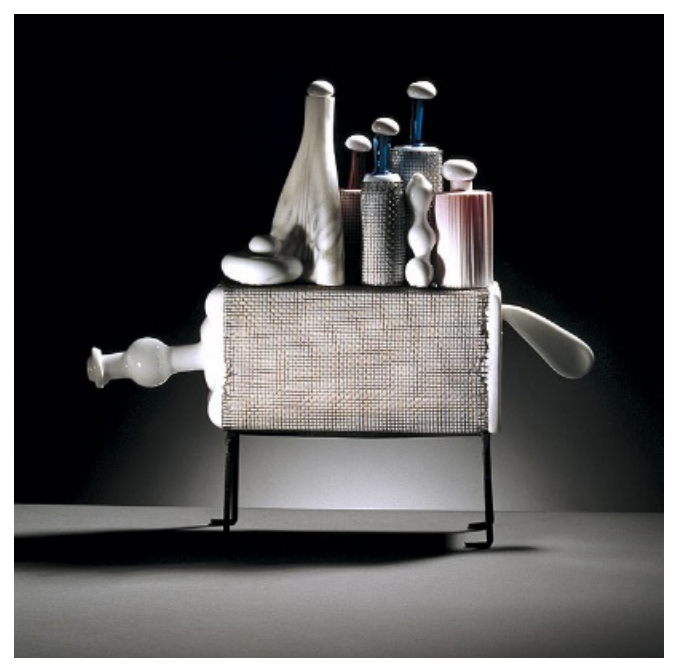

Figure 10. Markku Salo; Overload, 1996; fixed blown glass into wire mesh; courtesy of Markku Salo, used with permission. 


\section{Artists Combining Glass with Ceramic Inclusions, in Their Artistic Practice}

A few glass artists work with glass and ceramics, most tend to work the materials together either in a cold state using glue or in a hot state but the works often show signs of surface cracks, stresses and incompatibility. During the doctoral research of Kelly (2009), a literature review was carried out to identify which contemporary practitioners use glass and ceramics in their practice. This review demonstrated that glass and ceramics are rarely combined in studio practice; in 2009, she identified only forty-three contemporary artists that worked in both glass and ceramics, with only three artists using ceramic inclusions within glass in a hot state. This section of the paper will review a selection of glass artists that use ceramic inclusions in a hot state within their art glass. Since publishing her research, a further three known glass artists have emerged with two receiving direct help from Kelly to develop their work with her doctoral recipe for a compatible bone china body. The following glass artists combine ceramic inclusions with glass in a hot state, and their work will be discussed below: John Groth, Antoine Leperlier, June Morrison, Sally Resnick-Rockriver, Phirak Suon and Brandyn Callahan.

\subsection{John Groth}

Groth has developed a clay body that is compatible with the expansion rate of glass. His artworks combine clay and Bullseye glass in a hot state fusing them together to create sculptural forms which are then mounted on metal bases (see Figure 11); no visible cracks can be seen in the surface of his work, he started to work in both materials in 2000. His recent work has continued to develop the hot state combination of glass and ceramics; he has developed a range of formulas for ceramics that match the co-efficient of expansion (COE) of glass system 85 (plate glass), 90 (Bullseye) and 96 (Spectrum and Uroboros). He matches the COE by lining up the viscosity of the materials so that they move at the same time, it took him many years to develop his research.

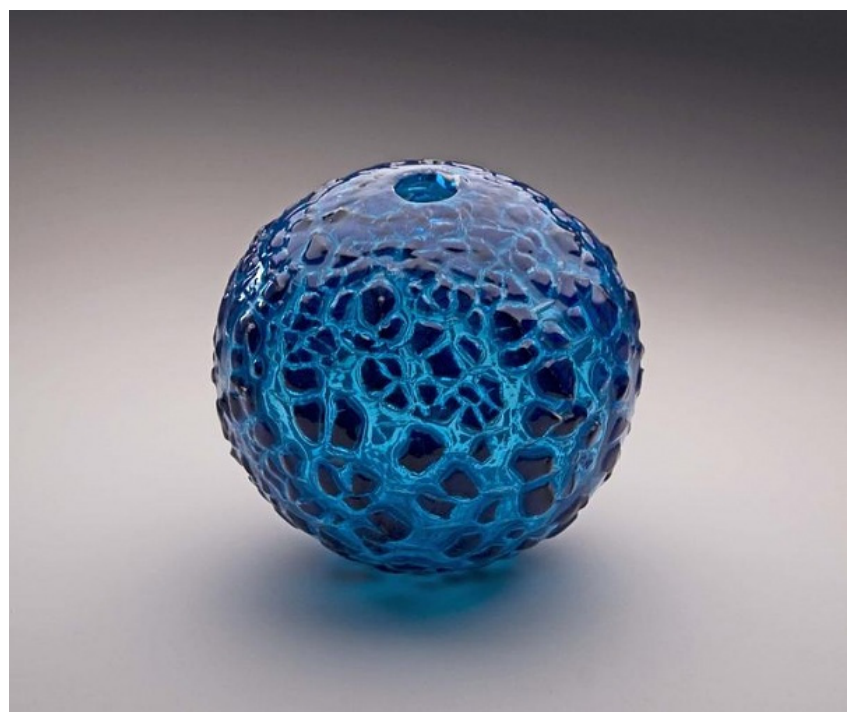

Figure 11. John Groth, blown glass, rolled up with ceramic, 2012. Courtesy of the artist.

\subsection{Antoine Leperlier}

Leperlier is renowned as a glass artist; he had some problems finding a ceramic which was compatible with glass and which he used to develop his sculptures (see Figure 12), on this occasion he sought advice from Kelly. Leperlier has for a long time tried to create 3D shapes within glass, which he describes as the fourth dimension. This internal space is like a snapshot of reality for him, and he sees it as an analogy of the mind, in which hollow thoughts float in space. He uses colours in his ceramics to form a connection between the 
two materials, and a flow within stability. He uses a pre-fired ceramic-based recipe that contains metal oxides which give colour to his work.

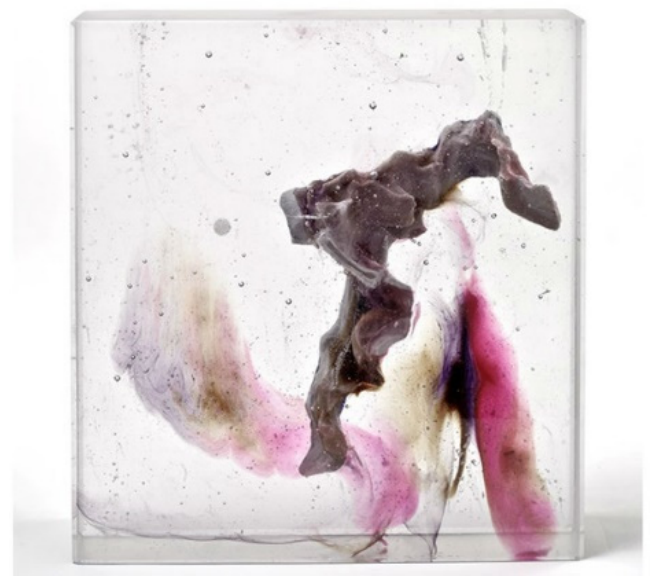

Figure 12. Antoine Leperlier; Verriales, 2013; glass with a bone china inclusion; photo credit: Serge Lechaczynski, used with permission.

\subsection{June Morrison}

Morrison worked closely with Kelly during her MFA studies at Edinburgh College of Art in 2009, during which time she created a new body of work which combined an adapted bone china recipe from Kelly with kiln cast glass. Her work explores the relationships and connections we create; one piece connects to the other to suggest an embrace (see Figure 13).

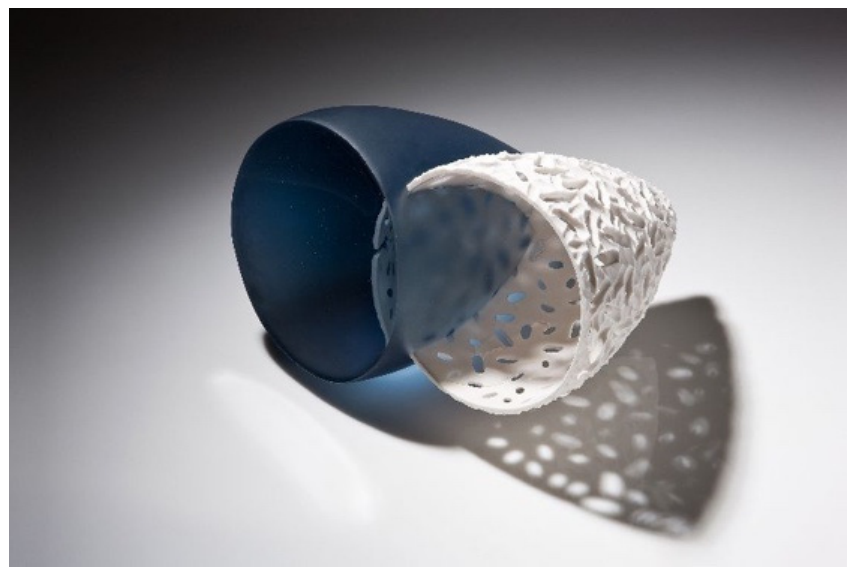

Figure 13. June Morrison, Embrace, 2009; bone china and kiln cast gaffer glass. Courtesy of the artist, used with permission.

\subsection{Sally Resnik Rockriver}

Rockriver generates hot state chemical reactions in her blown glass and ceramic artworks (Figure 14); she creates "geochemical formations" through high temperature crystal growth. She started using melted glass on her ceramics in 1993 to form crystalline glazes and in 1996 she applied ceramic glazes and metal oxides to her hot blown glass. Rockriver uses "failure" to produce works she calls "self-blown forms". In hot casting, she uses materials with a higher melting point because she is combining the hot liquid glass with chemicals to make self-blown bubbles. The spherical forms are influenced by the reactive effect of heated chemicals. By trapping ceramic glazes into molten glass, the hot salts release a gas that provides enough pressure to blow a bubble. The resulting form is a hollow ball with exploded powder bouncing around the interior. When the gases remain 
trapped, they deposit a dark metallic smoke. Escape holes are melted into some pieces to allow fumes to escape, this results in a clear sparkling dome (see Figure 14).

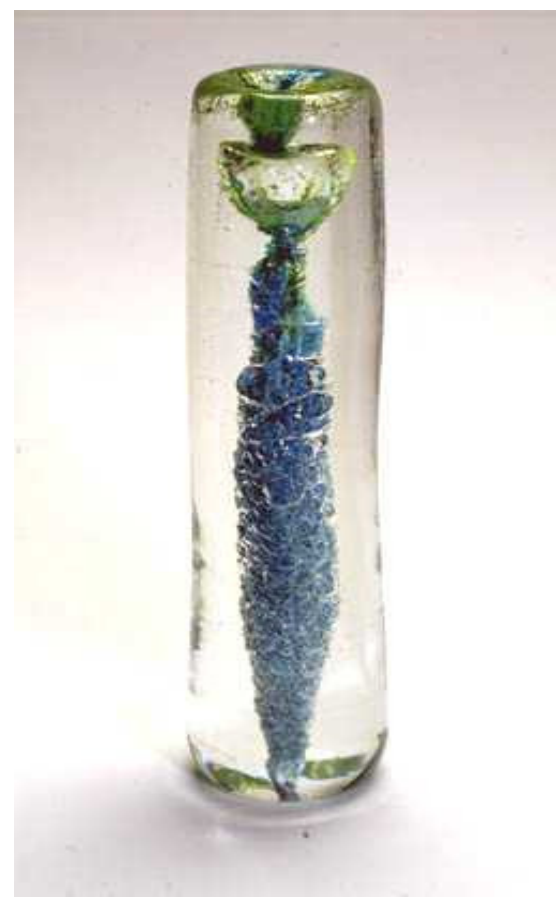

Figure 14. Sally Resnik Rockriver; Copper Rising, 2004; courtesy of the artist, used with permission.

In her own doctoral research, Bialek had the opposite goal of preventing the surfaces of the materials used in the experiments from adhering to each other. This involved preventing metal from oxidisation even at high temperatures (above $900{ }^{\circ} \mathrm{C}$ ) at the same time that it was in direct contact with glass. A search for a suitable separator or a process in which the separator could be produced alone was carried out by Bialek.

\subsection{Phirak Suon and Brandyn Callahan}

Suon and Callahan are artists based in Seattle; they met at the Pilchuck Glass School in 2016 and have collaborated ever since on a range of projects, which explore the intersection between materials through digital and traditional handicrafts. They combine their skill sets to explore traditional glassblowing techniques and 3D printing technology, most recently working with 3D printed ceramics which are encapsulated within hot glass (see Figure 15). Callahan has also explored the combination of glass and copper in his work.
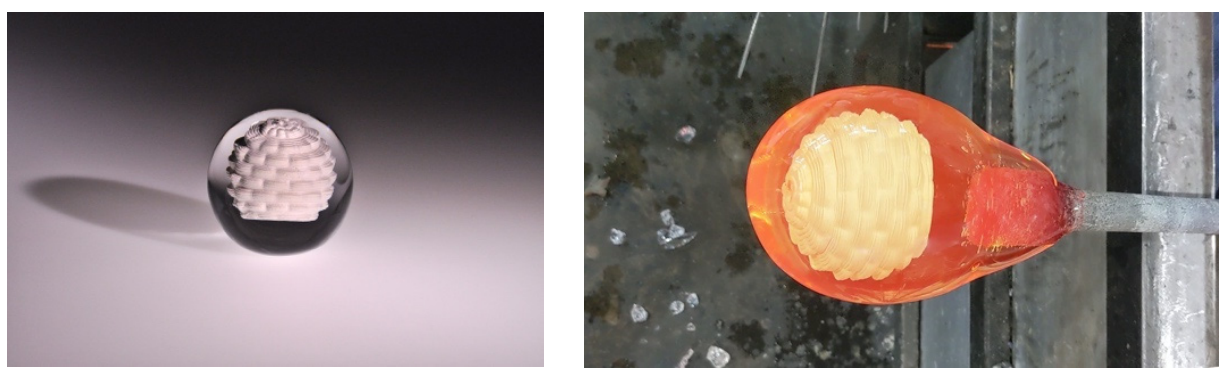

Figure 15. Suon and Callahan, research sample, pre-fired 3D printed ceramics encapsulated inclusion within hot glass, 2016, used with permission. 


\section{Artists That Combine Other Inclusions with Glass in Their Artistic Practice}

This final section of the paper will introduce the work of researchers that combine other inclusions in glass such as air inclusions, pre-made glass inclusions and print; the doctoral work of Ray Flavell, Joanne Mitchell, Goshka Bialek Choi Keeryong, Sheila Labatt and Dian Shi will be discussed.

\subsection{Dr Ray Flavell}

In 2001, Flavell completed his practice-based PhD at Edinburgh College of Art which was an investigation into the application of air inclusions in glass. Flavell followed on from the Swedish tradition of the ariel technique, which controls the shape and positioning of trapped air bubbles within blown glass forms by developing a new ariel technique that created very fine and detailed voids and air bubbles within blown glass vessels (see Figure 16) and flat glass. This study also demonstrated how the glass making process can be deconstructed to reveal new insights into studio practice.

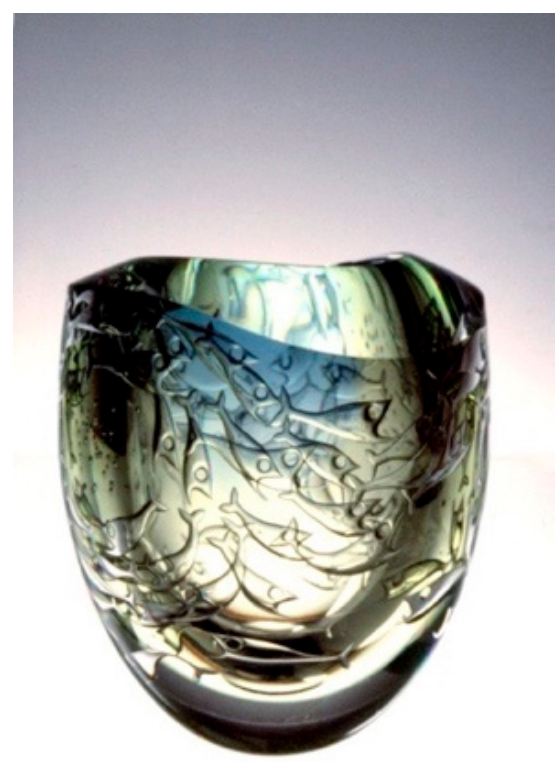

Figure 16. Ray Flavell, "Double Fish" blown glass with ariel technique, cold finished and polished, 2001. Courtesy of the artist, used with permission.

\subsection{Dr Joanne Mitchell}

In 2015, Mitchell completed her practice-based PhD at the University of Sunderland, which investigated the use of air inclusions in glass and was seen as a continuation of the doctoral work of Flavell. Her research explored the qualities of air and glass, often incorporated with human forms or text. Her doctoral research combines the innovative use of waterjet cutting and kiln-forming to control the form of air entrapment within the internal space of glass for personal expression, a unique working technique which she developed during her research (see Figure 17). Mitchell was also inspired by the doctoral work of Flavell and views her study as a continuation of his doctoral work into the use of ariel techniques on flat glass which she developed further using water jet cutting techniques and form sheet glass into sculptural 3-dimensional forms. 


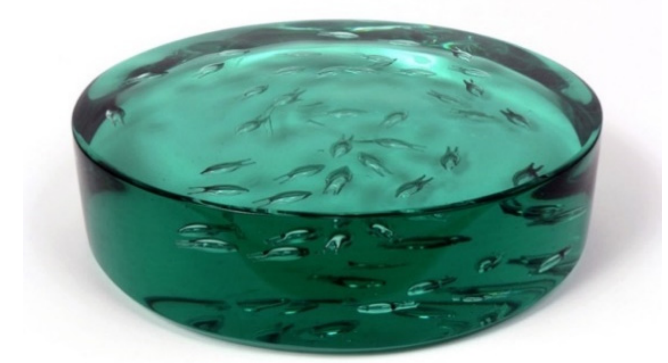

Figure 17. Joanne Mitchell, Host II, waterjet cut glass, kiln cast with ariel entrapment, 2015. Courtesy of the artist, used with permission.

\subsection{Goshka Bialek}

Bialek initially studied Fine Art and her early research (2000) was focused on the use of inclusions (such as fabrics, metals, organic objects, clay, and images) within kiln cast glass. She then focused on inclusions, such as prints, photographs, and holograms, and on the capabilities of controlling their shapes during the casting process. As a result of these studies, a novel technique of image transfer and 3D collages into glass was developed and the results were published by Petrie (2006). The application of print was predominantly used on the surfaces of cast and blown glass. The innovation was to combine casting, fusing and/or slumping techniques (see Figure 18) to create graphic image layers or 3D collages within the glass. An early example from 2001 incorporated the immersion of screen-printing, prints from engraved glass and hand painted images within glass. Printed images were applied onto the surface of cut-glass slabs and fired in a kiln; to control the flow of the printed inclusions, the slabs were composed of 3D collages and cast together. Applying the prints directly to the glass and controlling the shape of the inclusions was quite a straightforward process. However, to be able to assemble these complicated, cast large glass objects (sometimes up to $1800 \mathrm{~mm}$ in size) and to control the shapes of the inclusions during the casting, a great deal of experimentation was required. Bialek's innovative application methods of screen-printed inclusions in cast glass have since been used widely by glass artists, such as Dr Jeffrey Sarmiento who applies this method in his work.

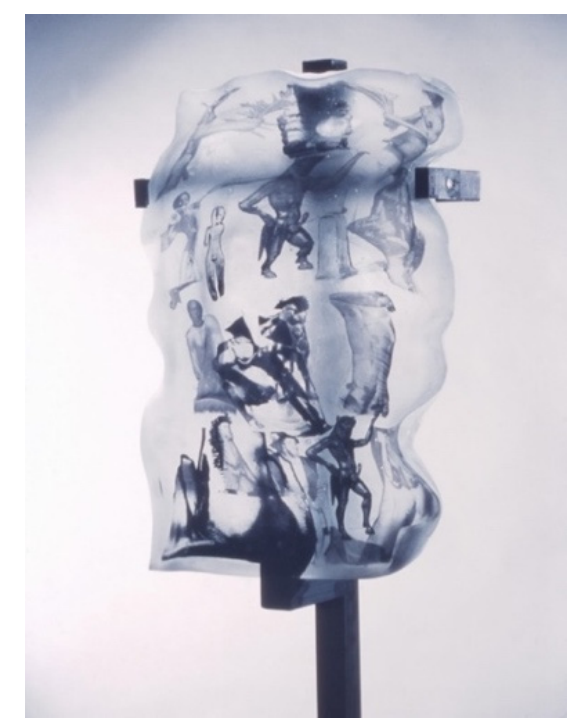

Figure 18. Goshka Bialek; Newspaper, 2002; inclusion of screen-printing images on transfer paper in glass; $180 \mathrm{~cm} \times 50 \mathrm{~cm} \times 30 \mathrm{~cm}$; photo credit: Tim Adams, used with permission. 


\subsection{Dr Choi Keeryong}

In 2016, Keeryong completed his practice practice-based PhD at Edinburgh College of Art, which investigated the development of an inlaid colouring technique for glassblowing. This research was greatly inspired by the doctoral work of Flavell and the decorative Korean Sanggam ceramic technique which was applied onto glass artefacts. Carefully incised motifs were sandblasted onto preformed glass parisons which created a void which could be filled with coloured glass powder, creating a delicately controlled inclusion of pure colour, to create a fine line drawing on the glass object, the lines can be applied with a wide range of colour variations (see Figure 19).

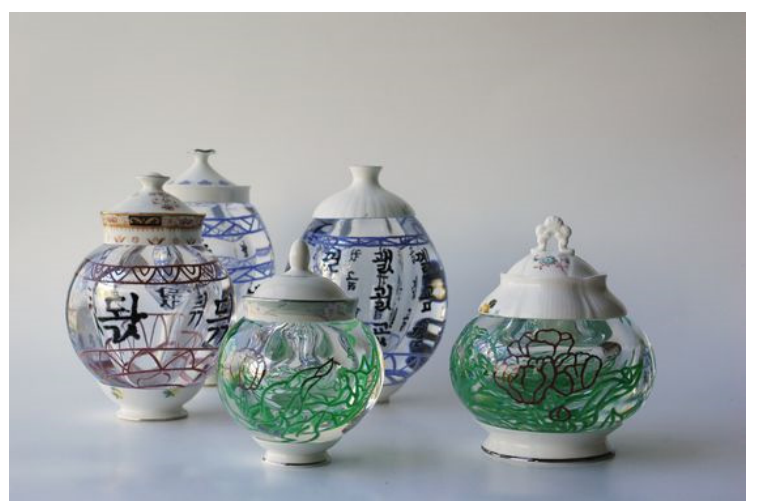

Figure 19. Choi Keeryong, Korean Glass; blown glass with colour inlay and English manufactured porcelain parts (2014). Courtesy of the artist, used with permission.

\subsection{Sheila Labbatt}

In 2017, Labbatt completed her practice-based PhD at the Royal College of Art, which explored how cast glass could be infused with a sense of spontaneity and gesture that evoke the fluid, and expressionistic immediacy of Chinese brush and ink painting (see Figure 20). She manipulates flameworked and powder inclusions using bubbles, voids and physical tools to emulate the rhythm and subtleties of Chinese landscape and calligraphy, in the third dimension. Her work also explores the material similarities between ink and glass, including their liquid properties and their ability to be worked as opaque or translucent (Labatt 2018).

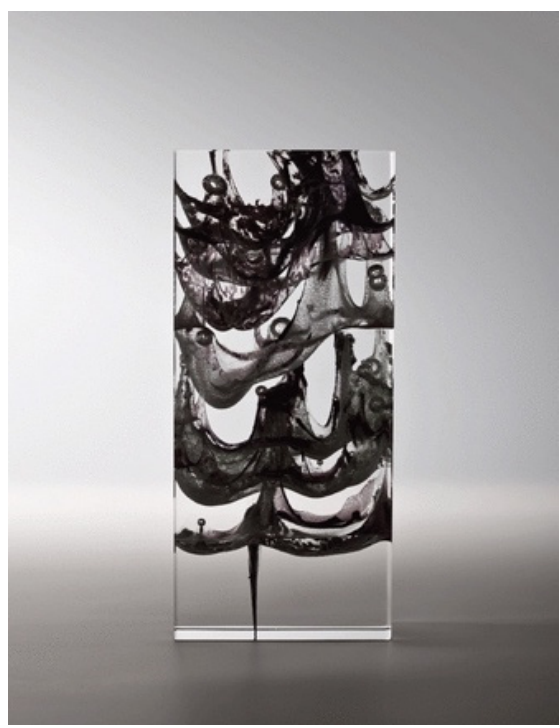

Figure 20. Sheila Labbatt, Ink Pot, 2012. Soda lime furnace glass, glass powders and solid flame worked inclusions and manipulate bubbles. Courtesy of the artist, used with permission. 


\subsection{Dr Dian Shi}

Shi completed her practice-based $\mathrm{PhD}$ at the University of Sunderland in 2020, which was an investigation into the application of metal oxides in studio glass to emulate Chinese ink of calligraphy within cast glass (see Figure 21). This research focused on the application of metal oxides within glass art inspired by Chinese calligraphy. Metal oxides were directly melted into the glass to create glass colour. Glass artists usually obtain glass colour from glass companies however, some artists are not satisfied with their palette and try to develop their own palette colour. This research extends the creative use of metal oxide in hot glass, lampworking glass and sheet glass. Chinese calligraphy is a fundamental part of traditional Chinese culture; this research asserts that the expression of ink shade is important in glass calligraphy art. This research redefines the use of brush and ink from a glass artist's perspective (Shi 2020).

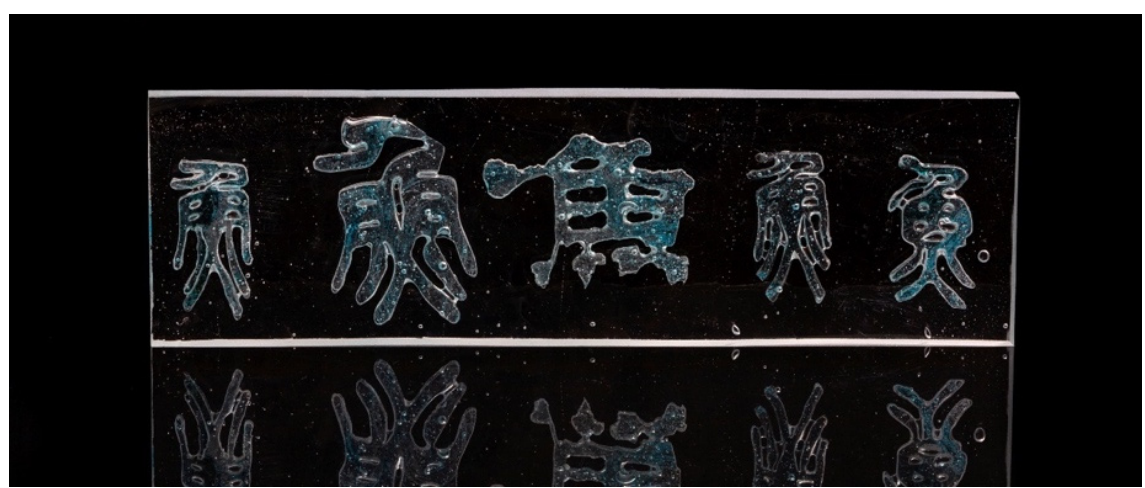

Figure 21. Dian Shi, Pictography series-Fish III, 2018. Water jet cut glass, with glass, oxides, and bubble inclusions. Courtesy of the artist, used with permission.

\section{Conclusions}

This paper has introduced how inclusions are used creatively within glass, by both artists and technologists, many of whom have anecdotally expressed their experiences in this field. A wide range of practice that has actively overcome difficult working challenges when working with inclusions has been reviewed. In addition, to traditional literature reviews of texts, data have been gathered through qualitative research methods such as semi-structured interview and observation techniques. This article has set the parameters of the field and has helped the authors to contextualise and develop a range of methods that detail how to apply intentional inclusions within glass. This paper has also given the authors the opportunity to reflect on their individual and collective artistic experiences of working with inclusions and to introduce updated applications and examples of their ongoing research since doctoral publication (see Figure 22).

The working definitions and techniques of inclusions within glass have been explored from these sources and perspectives to present and describe the approaches used by contemporary artists in the field. A key element in the approach to inclusions is in the understanding of material processes, which has been dealt with in a range of recent doctoral research projects. An in-depth study into the concept and use of inclusions plays an important part in understanding why artists are intrigued by the use of inclusions in glass. It is significant to recognise a collective response, from many of the artists discussed in the paper. This response has been defined and presented as an emergent body of practicebased research in which artists are collectively exploring the internal, inner space of glass for creative expression through the use of intentional inclusions. 


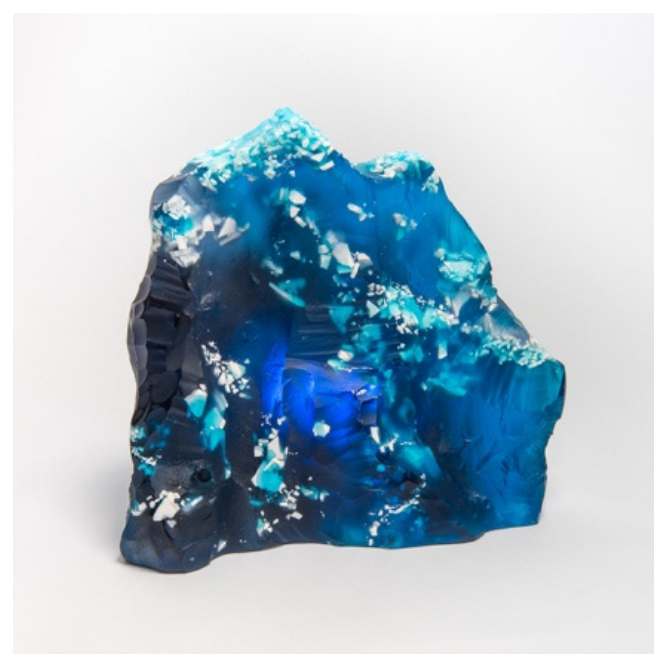

Figure 22. Kelly, Glacial Mind Landscape, 2019; turquoise kiln cast glass sculpture with compatible pre-fired bone china aggregate inclusions; photo credit: Marzena Ostromecka, used with permission.

The collaboration between artists and technologists has also been discussed as this is an important area in the continued development of these techniques over time. This extends, not only to successfully planned experimentation, but also to the understanding of how unexpected results, or "failures" can be used to expand knowledge of the processes involved and can even be used as a platform for new artistic endeavour and technological advances. This paper has identified the specific challenges and problems artists have had in the creative application of inclusions and the technological problems and limitations inclusions can bring to practice. This paper has fully defined and explored the variety of ways, both from a historical and contemporary perspective, that inclusions in glass, particularly metals and ceramics, have been combined together over many years.

Author Contributions: J.K., co-edited, co-written paper, Sections 1, 1.1, 2.1, 2.2 and 6-8; G.B., coedited, co-written paper, Sections 1, 1.2, 2, 2.1-2.3, 3-5, 6.2, 6.4 and 8. All authors have read and agreed to the published version of the manuscript.

Funding: This research received no external funding.

Acknowledgments: Thanks to all the artists and technologists that agreed to be interviewed and have their work included in this paper.

Conflicts of Interest: The authors declare no conflict of interest.

\section{References}

Bayley, Justine. 2014. A historian from The Museum Portable Antiquities Scheme. Telephone conversations with Goshka Bialek. January 14.

Bialek, Goshka. 2000. Application of Inclusions in Glass by Hot Glass Techniques. Bachelor's thesis, University of Sunderland, Sunderland, UK.

Bialek, Goshka. 2003. Application of Inclusions in Glass by Printed Images. Master's thesis, University of Sunderland, Sunderland, UK.

Bialek, Goshka. 2017. Inner Space in Sculpture: The Use of Metal Inclusions in Glass. Ph.D. thesis, University of Sunderland, Sunderland, UK.

Brachlow, Heike. 2012. Shaping Colour: Density, Light form in Solid Glass Sculpture. Ph.D. thesis, Royal College of Art, London, UK. Bray, Charles. 2001. Dictionary of Glass: Materials and Techniques, 2nd ed. London: A \& C Black.

Brill, Robert. H., and Sheldon Moll. 1963. Electron Beam Probe Microanalysis of Ancient Glass. In Advances in Glass Technology. New York: Plenum Press, Springer, Rakow Research Library and The Corning Museum of Glass, Part 2, pp. $293-302$.

Chrysopoulo, Anna. 2014. Cast Glass. The course description delivered by Anna Chrysopoulo. London: Westminster Adult College.

Clark-Monks, C., and J. M. Parker. 1980. Stones and Cord in Glass. Sheffield: Society of Glass Technology.

Cummings, Keith. 2002. A History of Glassforming. London: A\&C Black.

Cummings, Keith. 2007. Techniques of Kiln-Formed Glass. London: A\&C Black. First published 1997. 
Cummings, Keith. 2009a. Artist. Interview with Goshka Bialek. April 20.

Cummings, Keith. 2009b. Contemporary Kiln-Formed Glass. London: A\&C Black.

Donald, Ian. 2009. Glass-To-Meal Seals. Sheffield: Society of Glass Technology.

Flavell, Ray. 2001. The Development and Application of the Use of Encased Voids within the Body of Glass Artefacts as a Means of Drawing and Expression. Ph.D. thesis, Edinburgh College of Art, Edinburgh, UK.

Grose, David Frederick. 1989. The Toledo Museum of Art, Early Ancient Glass. 1600 BC to A.D. 50, 1st ed. New York: Hudson Hill Press in Association with the Toledo Museum of Art.

Hartwig, Jean. 2014. Art of Cameo Sulphides. Hartwig Jean-Meilleur Ouvrier de France (M.O.F). Available online: http:// paperweights.cristallerie-hartwig.com/history.html (accessed on 4 March 2014).

Jokelson, Paul. 1968. Sulphides, The Art of Cameo Incrustation, New ed. New York: Galahad Books.

Keeryong, Choi. 2016. Invented Exoticism: The Development of Artistic Forms and Inlaid Colouring Technique to Explore the Aesthetics of the Cultural Uncanny in an Individual's Visual Experience with Glass. Ph.D. thesis, University of Edinburgh, Edinburgh, UK.

Kelly, Jessamy. 2009. The Combination of Glass and Ceramics as a Means of Artistic Expression in Studio Practice. Ph.D. thesis, University of Sunderland, Sunderland, UK.

Kingery, W. David. 1986. High-Technology Ceramics Past, Present and Future. Westerville: The American Ceramic Society.

Labatt, Sheila. 2018. Glass as Ink: Seeking Spontaneity from the Casting Process. Ph.D. thesis, Royal College of Art, London, UK.

Layton, Peter. 1996. Glass Art. Seattle: University of Washington Press.

Lundstrom, Boyce. 2011. Kiln Fired Glass-Copper \& Metal Inclusions. California: Self-Published.

Matsuo, K. 1998. The Art and Technique of Pate de Verre. Tokyo: Tokyo Glass Institute.

McGregor, Lani. 1997. Bertil Vallien at Bullseye Glass. Portland: Bullseye Glass Co.

Mitchell, Joanne. 2015. Precision Air Entrapment through Applied Digital and Kiln Technologies: A New Technique in Glass Art. Ph.D. thesis, University of Sunderland, Sunderland, UK.

Oxford Advanced Learner's Dictionary. 2014. Definitions; Oxford: Oxford University Press. Available online: http://www. oxforddictionaries.com/definition/english/inclusion (accessed on 6 April 2014).

Petrie, Kevin. 2006. Glass and Print. London: A\&C Black/American Ceramic Society.

Shi, Dian. 2020. An Investigation into the Application of Metal Oxides in Studio Glass to Form a Model of Contemporary Chinese Glass Calligraphy. Ph.D. thesis, University of Sunderland, Sunderland, UK.

Stewart, Max. 2010. The Sense of my Screaming Skin. An Investigation into the Colouring Process of Amalric Walter (1870-1959) Using Metallic Salts in Pâtes-de-Verre. Ph.D. thesis, University of Edinburgh, Edinburgh, UK.

Strnad, Zdeněk. 1986. Glass-Ceramic Materials. Oxford: Elsevier.

The Corning Glass Dictionary. 2002. Corning Museum of Glass. Available online: https:/ /www.cmog.org/research/glass-dictionary (accessed on 20 June 2020).

The Retro Art Glass. 2014. Art Glass Terminology, Definitions. (Updated on 2014). Available online: http:/ / www.retroartglass.com/ page/14wn1/Glass_info/Glass_Definitions.html (accessed on 13 November 2009).

Vandenhoucke, Sylvie. 2003. Glass: Towards an Inner Space on Introducing Metal Oxides in Pâte de Verre Making. Master's thesis, Royal College of Art, London, UK.

Walker, Brad. 2010. Contemporary Fused Glass. Clemmons: Four Corners International, Inc. 